\title{
Association of nosocomial infections with delayed cerebral ischemia in aneurysmal subarachnoid hemorrhage
}

\author{
Paul M. Foreman, MD, ${ }^{1}$ Michelle Chua, BS, ${ }^{2}$ Mark R. Harrigan, MD, ${ }^{1}$ Winfield S. Fisher III, MD, ${ }^{1}$ \\ Nilesh A. Vyas, MD, ${ }^{3}$ Robert H. Lipsky, PhD, ${ }^{3}$ Beverly C. Walters, MD, MSc, FRCSC,, 3 \\ R. Shane Tubbs, PA-C, PhD, ${ }^{4}$ Mohammadali M. Shoja, MD, ${ }^{4}$ and Christoph J. Griessenauer, MD $^{1,5}$ \\ 'Department of Neurosurgery, University of Alabama at Birmingham, Alabama; ${ }^{2}$ Harvard Medical School, Harvard University, \\ Boston, Massachusetts; ${ }^{3}$ Department of Neurosciences, INOVA Health System, Fairfax, Virginia; ${ }^{4}$ Children's of Alabama, \\ Birmingham, Alabama; and ${ }^{5}$ Beth Israel Deaconess Medical Center, Division of Neurosurgery, Harvard University, Boston, \\ Massachusetts
}

OBJECTIVE Delayed cerebral ischemia (DCl) is a recognized complication of aneurysmal subarachnoid hemorrhage (aSAH) that contributes to poor outcome. This study seeks to determine the effect of nosocomial infection on the incidence of $\mathrm{DCl}$ and patient outcome.

METHODS An exploratory analysis was performed on 156 patients with aSAH enrolled in the Cerebral Aneurysm Renin Angiotensin System study. Clinical and radiographic data were analyzed with univariate analysis to detect risk factors for the development of $\mathrm{DCl}$ and poor outcome. Multivariate logistic regression was performed to identify independent predictors of $\mathrm{DCl}$.

RESULTS One hundred fifty-three patients with aSAH were included. DCI was identified in 32 patients $(20.9 \%)$. Nosocomial infection (odds ratio [OR] 3.5, 95\% confidence interval [Cl] 1.09-11.2, $p=0.04)$, ventriculitis (OR 25.3, 95\% Cl $1.39-458.7, p=0.03$ ), aneurysm re-rupture (OR 7.55, 95\% Cl 1.02-55.7, $p=0.05$ ), and clinical vasospasm (OR 43.4, $95 \% \mathrm{Cl} 13.1-143.4, p<0.01$ ) were independently associated with the development of $\mathrm{DCl}$. Diagnosis of nosocomial infection preceded the diagnosis of $\mathrm{DCl}$ in $15(71.4 \%)$ of 21 patients. Patients diagnosed with nosocomial infection experienced significantly worse outcomes as measured by the modified Rankin Scale score at discharge and 1 year $(p<0.01$ and $p=0.03$, respectively).

CONCLUSIONS Nosocomial infection is independently associated with $\mathrm{DCl}$. This association is hypothesized to be partly causative through the exacerbation of systemic inflammation leading to thrombosis and subsequent ischemia. http://thejns.org/doi/abs/10.3171/2015.10.JNS151959

KEY WORDS aneurysm; subarachnoid hemorrhage; infection; vasospasm; delayed cerebral ischemia; vascular disorders

$\Lambda$ NEURYSMAL subarachnoid hemorrhage (aSAH) is a unique form of hemorrhagic stroke associated with high morbidity and mortality. Delayed cerebral ischemia (DCI) is a recognized complication of aSAH that contributes to poor outcome, ${ }^{28,31}$ and it occurs in approximately $30 \%$ of patients. ${ }^{30}$ Early efforts to identify patients at risk for DCI focused on the diagnosis of large-vessel cerebral vasospasm. However, contemporary evidence suggests that DCI negatively affects outcome independent of angiographic vasospasm, suggesting that other factors are involved in the pathogenesis of DCI. ${ }^{37}$ Current understanding of the pathophysiology of DCI implicates cortical spreading depolarization, ${ }^{6,19}$ microthrombosis, ${ }^{34,38} \mathrm{im}$ paired autoregulation, ${ }^{27}$ alterations in microcirculation, ${ }^{25}$ and inflammatory pathways. ${ }^{22,23}$

While established risk factors for DCI include the amount of subarachnoid hemorrhage, clinical condition on admission, and smoking, ${ }^{4}$ an evolving knowledge of DCI

ABBREVIATIONS aSAH = aneurysmal subarachnoid hemorrhage; BAL = bronchoalveolar lavage; CARAS = Cerebral Aneurysm Renin Angiotensin System; CI = confidence interval; $\mathrm{CTA}=\mathrm{CT}$ angiography; $\mathrm{DCl}=$ delayed cerebral ischemia; $\mathrm{DSA}=$ digital subtraction angiography; $\mathrm{EVD}=$ external ventricular drain; $\mathrm{GCS}=\mathrm{Glasgow}$ Coma Scale; ICU = intensive care unit; $m R S=$ modified Rankin Scale; $O R=$ odds ratio; $T C D=$ transcranial Doppler ultrasonography; UTI = urinary tract infection.

SUBMITTED August 20, 2015. ACCEPTED October 22, 2015.

INCLUDE WHEN CITING Published online February 12, 2016; DOI: 10.3171/2015.10.JNS151959. 
has led to the identification of novel risk factors involving systemic inflammation. ${ }^{15,22,23}$ The contribution of nosocomial infections to systemic inflammation and subsequent DCI in patients with aSAH is not known. In this study we present a prospective cohort of patients with aSAH to evaluate the impact of nosocomial infection on the incidence of DCI.

\section{Methods}

A prospective cohort study was used to evaluate the effect of nosocomial infection on the incidence of DCI in patients with aSAH. All cases and controls were obtained from the Cerebral Aneurysm Renin Angiotensin System (CARAS) study, a prospective, blinded study designed to evaluate associations between the common genetic polymorphisms in the renin-angiotensin system and occurrence and rupture of cerebral aneurysms, development of cerebral vasospasm, and delayed cerebral ischemia, and outcome in aSAH. The study was started in December 2012 and completed enrollment in February 2015; final results are expected to be published in 2016.

\section{Study Population}

All patients presenting with aSAH to the University of Alabama at Birmingham and INOVA Health System were screened for inclusion in the CARAS study. The diagnosis of SAH was established on the basis of the admission CT scan or xanthochromia of CSF. A ruptured cerebral aneurysm was confirmed by CT angiography (CTA) or digital subtraction angiography (DSA). Exclusion criteria included age younger than 19 years and any associated genetic disease/syndrome that could account for the presence of an intracranial aneurysm (i.e., polycystic kidney disease, Turner syndrome, Noonan syndrome, Ehler-Danlos syndrome Type 4, Marfan syndrome, and neurofibromatosis Type 1), as well as systemic diseases (i.e., congestive heart failure, cirrhosis, etc.) that could affect the renin-angiotensin system. For the purposes of the current study, patients who died prior to 4 days postictus were also excluded. These patients presented with high Hunt and Hess grades and did not survive into the period of highest risk for the development of DCI.

Presence of a DCI was a secondary outcome measure in the CARAS study and all data were collected in a prospective manner. Demographic, clinical, and radiographic data were collected on all patients by the study principal investigator (C.J.G.) and co-principal investigator (P.M.F.).

\section{General Management}

Patients presenting with aSAH were treated in accordance with contemporary standards of care in the US, consisting of: intensive care unit (ICU) monitoring, treatment of hydrocephalus, early ( $<48$ hours) intervention for aneurysm treatment, oral nimodipine, maintenance of euvolemia, compression stockings, and sequential compression devices. Symptomatic vasospasm is treated with hyperdynamic therapy as first-line therapy. Hyperdynamic therapy includes strict avoidance of hypovolemia with a goal systolic blood pressure of more than $160 \mathrm{~mm} \mathrm{Hg}$, accomplished with either permissive hypertension or va- sopressor therapy. Patients with symptomatic vasospasm refractory to medical treatment are treated in the endovascular suite with intraarterial therapy at the discretion of the neurointerventionalist. Following discharge from the ICU, patients are transferred to a neurological step-down unit and a neurosurgical ward with specialty training in patients with aSAH. Of note, patients with external ventricular drains (EVDs) are not routinely treated with prophylactic antibiotics.

\section{Nosocomial Infection}

Nosocomial infections included bacteremia, pneumonia, and urinary tract infections (UTIs) that were diagnosed at any point during the hospital stay; ventriculitis was considered separately. Bacteremia was defined as a positive blood culture necessitating treatment with antibiotics; positive blood cultures that were believed to be a contaminant and therefore not treated were not considered. Pneumonia was defined as a consolidation on radiographic imaging, a positive bronchoalveolar lavage (BAL), or both a radiographic consolidation and positive BAL requiring treatment with antibiotics; radiographic consolidation due to another etiology (i.e., volume overload) and BAL cultures growing normal flora that were not treated with antibiotics were not considered. A UTI was defined as a positive urine culture or positive leukocyte esterase and/or positive nitrite on a urinalysis necessitating treatment with antibiotics; positive urine cultures or urinalyses representing colonization that were not treated with antibiotics were not considered.

Ventriculitis was defined as a positive CSF culture requiring treatment with antibiotics; positive CSF cultures believed to be contaminants were not treated with antibiotics and were not considered. Analysis of CSF consisting of cell count, glucose, protein, and culture are routinely sent on Monday, Wednesday, and Friday in all patients with an EVD.

Nosocomial infections were counted per patient. Thus, a patient with more than 1 nosocomial infection (i.e., UTI and pneumonia) was counted only once. However, a patient who developed a nosocomial infection (pneumonia, UTI, or bacteremia) and ventriculitis would be included twice, once in the nosocomial infection group and once in the ventriculitis group. When comparing the date of diagnosis of nosocomial infection or ventriculitis to the date of diagnosis of DCI, only the initial infection was considered.

\section{Vasospasm}

Angiographic vasospasm is defined as arterial narrowing appreciated on computed tomography angiography (CTA) or digital subtraction angiography (DSA) not due to atherosclerosis, catheter-induced vasospasm, or vessel hypoplasia. Additionally, vasospasm could be diagnosed with transcranial Doppler ultrasonography (TCD) findings of a peak systolic middle cerebral artery greater than $120 \mathrm{~mm} \mathrm{Hg}$ with a Lindegaard ratio greater than 3; TCD data are presented separately and not included in angiographic vasospasm. CTA, DSA, and TCD were used at the discretion of critical care and neurosurgical staff; not all patients were screened for angiographic vasospasm. 
Clinical vasospasm was defined as the development of a new focal or global neurological deficit, or deterioration of at least 2 points on the Glasgow Coma Scale (GCS), not explained by another clinical process including hydrocephalus, aneurysm rerupture, electrolyte disturbance, seizure, infection, fever, metabolic disturbance, cerebral edema, and surgical complication.

\section{Delayed Cerebral Ischemia}

CT and MR images were obtained due to clinical concern at the discretion of the critical care team and neurosurgical staff and routinely performed when the patient was deemed stable for transfer from the ICU to the ward. All patients were screened for DCI. Delayed cerebral ischemia was defined as low-density areas on CT that correspond to a vascular distribution or an MR image demonstrating a hyperintense area on a diffusion-weighted imaging sequence with a corresponding hypointense apparent diffusion coefficient sequence correlate that corresponds with a vascular territory. Infarctions or contusion noted on postoperative Day 1 imaging were considered procedurally related and were not considered DCI. Infarctions identified after postoperative Day 1 were considered DCI.

CT, CTA, and MRI were performed by trained technicians, interpreted by a neuroradiologist, and reviewed by neurosurgical staff. DSA was performed and interpreted by specialty-trained neurointerventionalists. TCD was performed by trained technicians and interpreted by specialty-trained neurosonologists. Disagreements were resolved though discussion of findings, with a final decision by the senior author (C.J.G.).

\section{Statistical Analysis}

Statistical analysis was performed using $\mathrm{R}$ version 3.1.1 (http://www.r-project.org). In univariate analysis, variables were compared between groups by the Wilcoxon rank-sum test for numerical variables and chi-square test for categorical variables. Statistical significance was defined as $\mathrm{p}<0.05$. Multivariate logistic regression was performed on candidate predictor variables to identify variables independently associated with DCI after controlling for potential confounders. Any variable associated with a $\mathrm{p}$ value around or below 0.1 in univariate analysis was included. Efforts to account for interactions and collinearity between variables were undertaken.

\section{Results}

One hundred fifty-six patients with confirmed aSAH were enrolled in the CARAS study from December 2012 to February 2015. Of these 156 patients, 3 were excluded due to early death ( $<4$ days postictus), leaving 153 patients for analysis in the current study. Patient characteristics are presented in Table 1 . Thirty-two patients (20.9\%) suffered DCI. Sixty-three patients (41.2\%) experienced a nosocomial infection (pneumonia, UTI, or bacteremia) and 4 patients (2.6\%) experienced ventriculitis. Aneurysm re-rupture occurred in 8 patients $(5.2 \%)$.

Twenty-one (65.6\%) of the patients with DCI were also diagnosed with a nosocomial infection. The diagnosis of infection preceded the diagnosis of DCI in 15 patients
(71.4\%) by an average of 4.7 days. Three (9.4\%) of the patients with DCI were also diagnosed with ventriculitis; the diagnosis of ventriculitis preceded the diagnosis of DCI in 1 patient. Five (15.6\%) of the 32 patients with DCI experienced aneurysm re-rupture.

Clinical vasospasm occurred in 35 (22.9\%) of the 153 patients in this study. Twenty-five $(78.1 \%)$ of the 32 patients with DCI were also diagnosed with clinical vasospasm.

\section{Risk Factors for $\mathrm{DCl}$ \\ Univariate Analysis}

Patients diagnosed with DCI were significantly more likely to have a lower GCS score $(p=0.03)$ and a higher Hunt and Hess grade $(\mathrm{p}=0.01)$. Patients with DCI were also more likely to present more than 2 days from the onset of symptoms $(p=0.05)$, demonstrate evidence of cerebral edema on CT $(p<0.01)$, require intubation $(\mathrm{p}<0.01)$, receive an antiepileptic drug $(\mathrm{p}=0.01)$, and experience aneurysm re-rupture $(\mathrm{p}=0.01)$.

Forty-two patients (34.7\%) without DCI and 21 (65.6\%) with DCI were diagnosed with a nosocomial infection that required treatment with antibiotics $(\mathrm{p}<0.01)$. One $(0.8 \%)$ patient without DCI and $3(9.4 \%)$ with DCI were diagnosed with ventriculitis that required treatment with antibiotics $(\mathrm{p}=0.04)$.

Angiographic and clinical vasospasm were significantly associated with the development of DCI $(p<0.01)$. Confirmation of the diagnosis of vasospasm by CTA or DSA was not available for 89 patients without DCI and 12 patients with DCI. Evidence of vasospasm by TCD measurements was not significantly associated with DCI ( $\mathrm{p}=$ $0.15)$; TCD data were not available for 70 patients without DCI and 18 patients with DCI (Table 1).

\section{Multivariate Analysis}

Based on statistical and clinical significance, the following variables were selected for multivariate regression: GCS score at presentation, Hunt and Hess grade, days to admission, clinical vasospasm, cerebral edema, nosocomial infection, intubation, cardiovascular instability, rerupture, hyponatremia, ventriculitis, and treatment with antiepileptic drugs. The best-fitting multivariate logistic regression model included DCI as the dependent variable with clinical vasospasm, nosocomial infection, re-rupture, and ventriculitis as the independent variables. Multivariate analysis identified nosocomial infection (odds ratio [OR] 3.5, 95\% confidence interval [CI] 1.09-11.2, p = 0.04 ), ventriculitis (OR 25.3, 95\% CI 1.39-458.7, $\mathrm{p}=0.03$ ), re-rupture (OR 7.55, 95\% CI 1.02-55.7, $\mathrm{p}=0.05)$, and clinical vasospasm (OR 43.4, 95\% CI 13.1-143.4, p < 0.01) as independent predictors of DCI (Table 2).

\section{Outcome}

Patients diagnosed with a nosocomial infection experienced poorer outcomes than patients not diagnosed with a nosocomial infection. Dichotomized (0-2 and 3-6) modified Rankin Scale (mRS) scores at discharge and 1 year were significantly different $(p<0.01$ and $p=0.03$, respectively) in patients with aSAH diagnosed with a nosocomial infection compared with those who were not (Table 3). 
TABLE 1. Univariate analysis of risk factors for $\mathrm{DCl}^{*}$

\begin{tabular}{|c|c|c|c|}
\hline Characteristic & $\begin{array}{c}\text { No DCl } \\
(n=121)\end{array}$ & $\mathrm{DCl}(\mathrm{n}=32)$ & $p$ Value \\
\hline Mean age \pm SD (yrs) & $54.2 \pm 12.9$ & $57.3 \pm 10.6$ & 0.42 \\
\hline Race & & & 0.06 \\
\hline White & $64(52.9)$ & $24(75.0)$ & \\
\hline African American & $52(43.0)$ & $8(25.0)$ & \\
\hline Other & $5(4.1)$ & $0(0)$ & \\
\hline Female & $89(73.6)$ & $26(81.3)$ & 0.51 \\
\hline Male & $32(26.4)$ & $6(18.8)$ & \\
\hline Mean BMI \pm SD & $29.4 \pm 7.5$ & $28.7 \pm 7.7$ & 0.56 \\
\hline Ischemic vascular disease & $7(5.8)$ & $4(12.5)$ & 0.36 \\
\hline Hypertension & $71(58.7)$ & $20(62.5)$ & 0.85 \\
\hline Diabetes mellitus & $9(7.4)$ & $3(9.4)$ & 1 \\
\hline Preadmission statin & $14(11.6)$ & $7(21.9)$ & 0.22 \\
\hline $\begin{array}{l}\text { Preadmission antithrombotic } \\
\text { treatment } \\
\text { None } \\
\text { Antiplatelet } \\
\text { Anticoagulation }\end{array}$ & $\begin{array}{c}105(86.8) \\
13(10.7) \\
3(2.5)\end{array}$ & $\begin{array}{c}30(93.8) \\
1(3.1) \\
1(3.1)\end{array}$ & 0.41 \\
\hline $\begin{array}{l}\text { Smoking } \\
\text { None } \\
\text { Former } \\
\text { Current }\end{array}$ & $\begin{array}{l}47(38.8) \\
13(10.7) \\
61(50.4)\end{array}$ & $\begin{array}{r}12(37.5) \\
6(18.8) \\
14(43.7)\end{array}$ & 0.46 \\
\hline $\begin{array}{l}\text { Alcohol } \\
\text { None } \\
\text { Former } \\
\text { Current }\end{array}$ & $\begin{array}{l}53(43.8) \\
17(14.0) \\
51(42.1)\end{array}$ & $\begin{array}{r}16(50.0) \\
6(18.8) \\
10(31.2) \\
\end{array}$ & 0.51 \\
\hline Illicit sympathomimetics & $8(6.6)$ & $1(3.1)$ & 0.75 \\
\hline Marijuana & $10(8.3)$ & $3(9.4)$ & 1 \\
\hline Family history of aneurysms & $13(10.7)$ & $2(6.3)$ & 0.67 \\
\hline $\begin{array}{l}\text { Hypertension (>140/90) on } \\
\text { admission }\end{array}$ & $82(67.8)$ & $26(81.3)$ & 0.20 \\
\hline GCS score at presentation & & & 0.03 \\
\hline $3-7$ & $29(24.0)$ & $15(46.9)$ & \\
\hline $8-12$ & $3(2.5)$ & $0(0)$ & \\
\hline $13-15$ & $89(73.6)$ & $17(53.1)$ & \\
\hline Hunt \& Hess Grade & & & 0.01 \\
\hline 1 & $15(12.4)$ & 1 (3.1) & \\
\hline 2 & $62(51.2)$ & $10(31.3)$ & \\
\hline 3 & $24(19.8)$ & $9(28.1)$ & \\
\hline 4 & $16(13.2)$ & $7(21.9)$ & \\
\hline 5 & $4(3.3)$ & $5(15.6)$ & \\
\hline Fisher Grade & & & 0.37 \\
\hline 1 & $3(2.5)$ & $1(3.1)$ & \\
\hline 2 & $19(15.7)$ & $1(3.1)$ & \\
\hline 3 & $68(56.2)$ & $22(68.8)$ & \\
\hline 4 & $31(25.6)$ & $8(25.0)$ & \\
\hline $\begin{array}{l}\text { Posterior circulation aneu- } \\
\text { rysm }\end{array}$ & $23(19.0)$ & $5(15.6)$ & 0.86 \\
\hline Aneurysm size $(\mathrm{mm})$ & & & 0.88 \\
\hline$<7$ & $78(64.5)$ & $19(59.4)$ & \\
\hline $7-12$ & $38(31.4)$ & $12(37.5)$ & \\
\hline $13-24$ & $4(3.3)$ & 1 (3.1) & \\
\hline$>24$ & $1(0.8)$ & 0 & \\
\hline
\end{tabular}

CONTINUED IN NEXT COLUMN »
» CONTINUED FROM PREVIOUS COLUMN

TABLE 1. Univariate analysis of risk factors for $\mathrm{DCl}^{*}$

\begin{tabular}{|c|c|c|c|}
\hline Characteristic & $\begin{array}{c}\text { No DCl } \\
(n=121)\end{array}$ & $\mathrm{DCl}(\mathrm{n}=32)$ & p Value \\
\hline EVD & $91(75.2)$ & $28(87.5)$ & 0.21 \\
\hline $\begin{array}{l}\text { Treatment } \\
\text { Clipping } \\
\text { Coiling } \\
\text { None } \\
\text { Selverstone }\end{array}$ & $\begin{array}{c}62(51.2) \\
57(47.1) \\
1(0.8) \\
1(0.8)\end{array}$ & $\begin{array}{l}17(53.1) \\
14(43.8) \\
1(3.1) \\
0\end{array}$ & 0.71 \\
\hline $\begin{array}{l}\text { Time from symptom onset to } \\
\text { admission } \\
0-2 \text { days } \\
>2 \text { days }\end{array}$ & $\begin{array}{c}5(4.1) \\
116(95.9)\end{array}$ & $\begin{array}{r}5(15.6) \\
27(84.4)\end{array}$ & 0.05 \\
\hline Clinical vasospasm & $10(8.3)$ & $25(78.1)$ & $<0.01$ \\
\hline Angiographic vasospasm† & $10(31.3)$ & $20(100)$ & $<0.01$ \\
\hline TCD vasospasm $\ddagger$ & $31(60.8)$ & $12(85.7)$ & 0.15 \\
\hline Cerebral edema & $21(17.4)$ & $16(50.0)$ & $<0.01$ \\
\hline Nosocomial infection & $42(34.7)$ & $21(65.6)$ & $<0.01$ \\
\hline Intubation & $28(23.1)$ & $19(59.4)$ & $<0.01$ \\
\hline Cardiovascular instability & $20(16.5)$ & $10(31.3)$ & 0.11 \\
\hline Re-rupture & $3(2.5)$ & $5(15.6)$ & 0.01 \\
\hline Hyponatremia & $49(40.5)$ & $7(21.9)$ & 0.08 \\
\hline Ventriculitis & $1(0.8)$ & $3(9.4)$ & 0.04 \\
\hline Antiepileptic drug & $44(36.4)$ & $21(65.6)$ & 0.01 \\
\hline \multicolumn{4}{|c|}{$\begin{array}{l}\text { BMI = body mass index. } \\
\text { * All data given as number (\%) unless otherwise indicated. } \\
\text { † Angiographic data were not available for } 89 \text { patients without } \mathrm{DCl} \text { or } 12 \\
\text { patients with DCl. } \\
\text { † TCD data were not available for } 70 \text { patients without } \mathrm{DCl} \text { or } 18 \text { patients with } \\
\text { DCl. }\end{array}$} \\
\hline
\end{tabular}

\section{Discussion}

Delayed cerebral ischemia occurs in approximately $30 \%$ of patients with aSAH and contributes to poor outcome through vasospasm-dependent and -independent mechanisms. ${ }^{28,30,31,37}$ Early identification of those patients at increased risk has the potential to reduce neurological morbidity and mortality rates. An evolving understanding of the pathophysiology of symptomatic vasospasm and DCI has led to the identification of novel risk factors including systemic inflammation. . 15,23 This study sought to assess the role of nosocomial infection with respect to DCI and outcome in patients presenting with aSAH.

\section{Nosocomial Infection and DCI}

Subarachnoid hemorrhage-induced immunodepression predisposes patients to bacterial infection and is most pronounced in neurologically symptomatic patients. ${ }^{32}$ Nosocomial infections occur in approximately 26\%-37\% of patients with aSAH and contribute to poor outcome. ${ }^{2,9,18}$ The current series experienced a nosocomial infection rate of $41 \%$. Infection was identified as a statistically significant independent predictor of DCI with an OR of 3.5. While some authors have hypothesized that DCI predisposes patients to the development of nosocomial infection, ${ }^{9}$ we contend that an additional clinical interplay is occurring. 
TABLE 2. Independent predictors of DCI

\begin{tabular}{lcccc}
\hline \multicolumn{1}{c}{ Predictor } & Multivariate Coefficient & Standard Error & OR $(95 \% \mathrm{Cl})$ & $\mathrm{p}$ Value \\
\hline Clinical vasospasm & 3.77 & 0.61 & $43.4(13.1-143.4)$ & $<0.01$ \\
\hline Nosocomial infection & 1.25 & 0.60 & $3.5(1.09-11.2)$ & 0.04 \\
\hline Re-rupture & 2.02 & 1.02 & $7.55(1.02-55.7)$ & 0.05 \\
\hline Ventriculitis & 3.23 & 1.48 & $25.3(1.39-458.7)$ & 0.03 \\
\hline
\end{tabular}

The majority of infection diagnoses preceded the diagnosis of DCI in the current series. Thus, we hypothesize that while DCI predisposes patients to infectious complications, infection predisposes patients to the development of DCI. Infection is a recognized precipitant of systemic inflammation leading to thrombocytosis, ${ }^{11}$ leukocytosis, and release of inflammatory cytokines (namely, interleukin-6), ${ }^{24}$ all of which have been implicated in the development of DCI. ${ }^{5,15,22,23}$ The role of systemic inflammation in the pathogenis of DCI involves increased concentration of adhesion molecules, cytokine-mediated vasoconstriction, upregulation of coagulation pathways, and downregulation of anticoagulation pathways..$^{20,26,38}$

Ventriculitis is a rare complication in patients with aSAH despite the frequent use of EVDs in the setting of SAH-induced immunodepression, occurring in approximately $1 \%-5 \%$ of patients (2.4\% in the current series). ${ }^{9,35}$ The development of ventriculitis was associated with a 25 times greater risk of DCI in the current series and preceded the diagnosis of DCI in 1 of 3 cases. Ventriculitis is most commonly a complication of prolonged external ventricular drainage. ${ }^{16}$ Therefore, patients at highest risk for ventriculitis tend to be sicker patients requiring prolonged CSF diversion (i.e., high Hunt and Hess grades); these patients are also known to be at high risk for DCI, suggesting an association rather than causation. ${ }^{1,4}$ An alternative explanation could involve a marked inflammatory response within the CNS with subsequent intrathecal leukocytosis and cytokine release. ${ }^{13,33}$ This inflammation could contribute to DCI through similar mechanisms as systemic inflammation.

Further investigation into the temporal course of nosocomial infection, the systemic inflammatory response, and the development of DCI will need to be undertaken to better define a causative relationship. It is likely that causation is not linear, but rather a complex interplay between dynamic systems.

TABLE 3. Outcome with respect to nosocomial infection

\begin{tabular}{cccc}
\hline & \multicolumn{2}{c}{ Nosocomial Infection (\%) } & \\
\cline { 2 - 3 } mRS Score & No $(\mathrm{n}=90)$ & Yes $(\mathrm{n}=63)$ & p Value \\
\hline Discharge & & & $<0.01$ \\
$0-2$ & $61(67.8)$ & $13(20.6)$ & \\
$3-6$ & $29(32.2)$ & $50(79.4)$ & \\
\hline $1 \mathrm{yr}^{*}$ & & & 0.03 \\
$0-2$ & $55(82.1)$ & $20(52.6)$ & \\
$3-6$ & $12(17.9)$ & $18(47.4)$ & \\
\hline
\end{tabular}

* Clinical follow-up was not available for 23 patients without infection or 25 patients with infection at 1 year.

\section{Nosocomial Infection and Outcome}

Medical complications are common in patients with

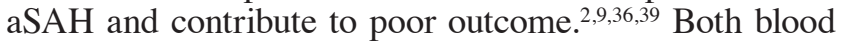
stream infection and pneumonia have been identified as independent predictors of death or severe disability in aSAH. ${ }^{9}$ While the association between nosocomial infection and poor outcome is intuitive, the potential pathophysiological mechanism proposed by the current series is novel. The poor outcomes associated with nosocomial infection in patients with aSAH may be related to a propensity for the development of DCI, an established poor prognostic indicator. ${ }^{28,31,37}$

\section{Aneurysm Re-Rupture and DCl}

The re-rupture of an intracranial aneurysm is the most feared early complication in patients presenting with aSAH. The risk of re-rupture is nearly $20 \%$ in the first 24 hours, ${ }^{10,14}$ leading to guideline recommendations for early treatment. ${ }^{3}$ Data regarding the effect of aneurysm re-rupture on the incidence of cerebral ischemia is mixed, with more recent data finding no difference. ${ }^{12,21}$ However, the present study identified aneurysm re-rupture as a statistically significant independent risk factor for DCI, with an OR of nearly 8 . This finding is consistent with the association between increasing clot burden and increasing rates of vasospasm and DCI. ${ }^{1,8,17}$

\section{Clinical Vasospasm and DCl}

Clinical vasospasm occurred in $22.8 \%$ of the total study population and was independently associated with the development of DCI in multivariate analysis. This association is expected and has been identified in previous studies. ${ }^{7,29}$ Clinical vasospasm has been identified as a potentially treatable factor associated with infarction. ${ }^{7}$ While focal clinical vasospasm may be easily appreciated through the identification of localizing signs, the more common diffuse vasospasm may present more insidiously. ${ }^{29}$ Therefore a high index of suspicion must be maintained in an effort to quickly diagnose and treat prior to the development of cerebral infarction.

\section{Limitations of the Study}

This study has several limitations. The study population is relatively small, leading to concerns of statistical power. While DCI was defined as imaging evidence of cerebral infarction, the timing of diagnosis can vary. Symptomatic ischemia in neurologically well patients may be identified more quickly than symptomatic ischemia in neurologically ill patients or asymptomatic ischemia. This could lead to misinterpretation of the clinical timeline with regard to the diagnosis of infection and DCI. Another 
possibility is that the infection itself led to impaired neurological function, prompting increased surveillance in these patients. This has the potential to falsely elevate the rate of diagnosis of DCI in patients with infection. In addition, data on other parameters such as TCD results and clinical follow-up were lacking in some patients.

\section{Conclusions}

Nosocomial infection is independently associated with the development of DCI in patients with aSAH. It is hypothesized that this association is, in part, causative with nosocomial infection predisposing patients to the development of DCI by exacerbating the systemic inflammatory response leading to thrombosis and subsequent ischemia.

\section{Acknowledgments}

We would like to thank the neurosurgical research coordinators at INOVA Health System for their work and contribution to the CARAS study. We would also like to thank the Brain Aneurysm Foundation for their generous support of the CARAS study.

\section{References}

1. Adams HP Jr, Kassell NF, Torner JC, Haley EC Jr: Predicting cerebral ischemia after aneurysmal subarachnoid hemorrhage: influences of clinical condition, CT results, and antifibrinolytic therapy. A report of the Cooperative Aneurysm Study. Neurology 37:1586-1591, 1987

2. Badjatia N, Monahan A, Carpenter A, Zimmerman J, Schmidt JM, Claassen J, et al: Inflammation, negative nitrogen balance, and outcome after aneurysmal subarachnoid hemorrhage. Neurology 84:680-687, 2015

3. Connolly ES Jr, Rabinstein AA, Carhuapoma JR, Derdeyn CP, Dion J, Higashida RT, et al: Guidelines for the management of aneurysmal subarachnoid hemorrhage: a guideline for healthcare professionals from the American Heart Association/American Stroke Association. Stroke 43:1711-1737, 2012

4. de Rooij NK, Rinkel GJ, Dankbaar JW, Frijns CJ: Delayed cerebral ischemia after subarachnoid hemorrhage: a systematic review of clinical, laboratory, and radiological predictors. Stroke 44:43-54, 2013

5. Dhar R, Diringer MN: The burden of the systemic inflammatory response predicts vasospasm and outcome after subarachnoid hemorrhage. Neurocrit Care 8:404-412, 2008

6. Dreier JP, Major S, Manning A, Woitzik J, Drenckhahn C, Steinbrink J, et al: Cortical spreading ischaemia is a novel process involved in ischaemic damage in patients with aneurysmal subarachnoid haemorrhage. Brain 132:1866-1881, 2009

7. Fergusen S, Macdonald RL: Predictors of cerebral infarction in patients with aneurysmal subarachnoid hemorrhage. Neurosurgery 60:658-667, 2007

8. Fisher CM, Kistler JP, Davis JM: Relation of cerebral vasospasm to subarachnoid hemorrhage visualized by computerized tomographic scanning. Neurosurgery 6:1-9, 1980

9. Frontera JA, Fernandez A, Schmidt JM, Claassen J, Wartenberg KE, Badjatia N, et al: Impact of nosocomial infectious complications after subarachnoid hemorrhage. Neurosurgery 62:80-87, 2008

10. Fujii Y, Takeuchi S, Sasaki O, Minakawa T, Koike T, Tanaka R: Ultra-early rebleeding in spontaneous subarachnoid hemorrhage. J Neurosurg 84:35-42, 1996

11. Griesshammer M, Bangerter M, Sauer T, Wennauer R, Bergmann L, Heimpel H: Aetiology and clinical significance of thrombocytosis: analysis of 732 patients with an elevated platelet count. J Intern Med 245:295-300, 1999
12. Gruber A, Dietrich W, Czech T, Richling B: Recurrent aneurysmal subarachnoid haemorrhage: bleeding pattern and incidence of posthaemorrhagic ischaemic infarction. Br J Neurosurg 11:121-126, 1997

13. Hashim IA, Walsh A, Hart CA, Shenkin A: Cerebrospinal fluid interleukin-6 and its diagnostic value in the investigation of meningitis. Ann Clin Biochem 32:289-296, 1995

14. Inagawa T, Kamiya K, Ogasawara H, Yano T: Rebleeding of ruptured intracranial aneurysms in the acute stage. Surg Neurol 28:93-99, 1987

15. Kasius KM, Frijns CJ, Algra A, Rinkel GJ: Association of platelet and leukocyte counts with delayed cerebral ischemia in aneurysmal subarachnoid hemorrhage. Cerebrovasc Dis 29:576-583, 2010

16. Kim JH, Desai NS, Ricci J, Stieg PE, Rosengart AJ, Härtl $\mathrm{R}$, et al: Factors contributing to ventriculostomy infection. World Neurosurg 77:135-140, 2012

17. Kistler JP, Crowell RM, Davis KR, Heros R, Ojemann RG, Zervas T, et al: The relation of cerebral vasospasm to the extent and location of subarachnoid blood visualized by CT scan: a prospective study. Neurology 33:424-436, 1983

18. Laban KG, Rinkel GJ, Vergouwen MD: Nosocomial infections after aneurysmal subarachnoid hemorrhage: time course and causative pathogens. Int J Stroke 10:763-766, 2015

19. Leng LZ, Fink ME, Iadecola C: Spreading depolarization: a possible new culprit in the delayed cerebral ischemia of subarachnoid hemorrhage. Arch Neurol 68:31-36, 2011

20. Levi M, van der Poll T, Büller HR: Bidirectional relation between inflammation and coagulation. Circulation 109:26982704, 2004

21. Lord AS, Fernandez L, Schmidt JM, Mayer SA, Claassen J, Lee K, et al: Effect of rebleeding on the course and incidence of vasospasm after subarachnoid hemorrhage. Neurology 78:31-37, 2012

22. McMahon CJ, Hopkins S, Vail A, King AT, Smith D, Illingworth KJ, et al: Inflammation as a predictor for delayed cerebral ischemia after aneurysmal subarachnoid haemorrhage. J Neurointerv Surg 5:512-517, 2013

23. Muroi C, Hugelshofer M, Seule M, Tastan I, Fujioka M, Mishima K, et al: Correlation among systemic inflammatory parameter, occurrence of delayed neurological deficits, and outcome after aneurysmal subarachnoid hemorrhage. Neurosurgery 72:367-375, 2013

24. Oda S, Hirasawa H, Shiga H, Nakanishi K, Matsuda K, Nakamua M: Sequential measurement of IL-6 blood levels in patients with systemic inflammatory response syndrome (SIRS)/sepsis. Cytokine 29:169-175, 2005

25. Ohkuma H, Manabe H, Tanaka M, Suzuki S: Impact of cerebral microcirculatory changes on cerebral blood flow during cerebral vasospasm after aneurysmal subarachnoid hemorrhage. Stroke 31:1621-1627, 2000

26. Osuka K, Suzuki Y, Tanazawa T, Hattori K, Yamamoto N, Takayasu M, et al: Interleukin-6 and development of vasospasm after subarachnoid haemorrhage. Acta Neurochir (Wien) 140:943-951, 1998

27. Otite F, Mink S, Tan CO, Puri A, Zamani AA, Mehregan A, et al: Impaired cerebral autoregulation is associated with vasospasm and delayed cerebral ischemia in subarachnoid hemorrhage. Stroke 45:677-682, 2014

28. Pegoli M, Mandrekar J, Rabinstein AA, Lanzino G: Predictors of excellent functional outcome in aneurysmal subarachnoid hemorrhage. J Neurosurg 122:414-418, 2015

29. Rabinstein AA, Friedman JA, Weigand SD, McClelland RL, Fulgham JR, Manno EM, et al: Predictors of cerebral infarction in aneurysmal subarachnoid hemorrhage. Stroke 35:1862-1866, 2004

30. Roos YB, de Haan RJ, Beenen LF, Groen RJ, Albrecht KW, Vermeulen M: Complications and outcome in patients with 
aneurysmal subarachnoid haemorrhage: a prospective hospital based cohort study in the Netherlands. J Neurol Neurosurg Psychiatry 68:337-341, 2000

31. Rosengart AJ, Schultheiss KE, Tolentino J, Macdonald RL: Prognostic factors for outcome in patients with aneurysmal subarachnoid hemorrhage. Stroke 38:2315-2321, 2007

32. Sarrafzadeh A, Schlenk F, Meisel A, Dreier J, Vajkoczy P, Meisel C: Immunodepression after aneurysmal subarachnoid hemorrhage. Stroke 42:53-58, 2011

33. Schoch B, Regel JP, Nierhaus A, Wichert M, Mueller OM, Sandalcioglu IE, et al: Predictive value of intrathecal interleukin- 6 for ventriculostomy-related Infection. Zentralbl Neurochir 69:80-86, 2008

34. Sehba FA, Mostafa G, Friedrich V Jr, Bederson JB: Acute microvascular platelet aggregation after subarachnoid hemorrhage. J Neurosurg 102:1094-1100, 2005

35. Singh TD, Maloney P, Rabinstein AA, Hocker S: Significance of routine cerebrospinal fluid analysis in subarachnoid hemorrhage. J Neurosurg Sci [epub ahead of print], 2015

36. Solenski NJ, Haley EC Jr, Kassell NF, Kongable G, Germanson T, Truskowski L, et al: Medical complications of aneurysmal subarachnoid hemorrhage: a report of the multicenter, cooperative aneurysm study. Participants of the Multicenter Cooperative Aneurysm Study. Crit Care Med 23:1007-1017, 1995

37. Vergouwen MD, Ilodigwe D, Macdonald RL: Cerebral infarction after subarachnoid hemorrhage contributes to poor outcome by vasospasm-dependent and -independent effects. Stroke 42:924-929, 2011

38. Vergouwen MD, Vermeulen M, Coert BA, Stroes ES, Roos
YB: Microthrombosis after aneurysmal subarachnoid hemorrhage: an additional explanation for delayed cerebral ischemia. J Cereb Blood Flow Metab 28:1761-1770, 2008

39. Wartenberg KE, Schmidt JM, Claassen J, Temes RE, Frontera JA, Ostapkovich N, et al: Impact of medical complications on outcome after subarachnoid hemorrhage. Crit Care Med 34:617-624, 2006

\section{Disclosures}

The authors report no conflict of interest concerning the materials or methods used in this study or the findings specified in this paper.

\section{Author Contributions}

Conception and design: Foreman, Griessenauer. Acquisition of data: Foreman, Griessenauer. Analysis and interpretation of data: Foreman, Chua, Griessenauer. Drafting the article: Foreman. Critically revising the article: Foreman, Harrigan, Fisher, Vyas, Lipsky, Walters, Tubbs, Shoja, Griessenauer. Reviewed submitted version of manuscript: Foreman, Harrigan, Griessenauer. Approved the final version of the manuscript on behalf of all authors: Foreman. Statistical analysis: Chua, Griessenauer. Study supervision: Foreman, Harrigan, Fisher, Griessenauer.

\section{Correspondence}

Paul M. Foreman, Department of Neurosurgery, University of Alabama at Birmingham, Faculty Office Tower 1005, 510 20th St. S., Birmingham, AL 35294. email: pforeman@uabmc.edu. 